\title{
INTEGRATED SURVEY TECHNIQUES: PRELIMINARY STUDIES FOR THE CONSERVATION OF VILLA GALVAGNINA
}

\author{
V.M. Nannei ${ }^{1}$, P.M. Farina ${ }^{2}$, G. Mirabella Roberti ${ }^{3}$, A. Sansonetti ${ }^{4}$ \\ ${ }^{1}$ Graduate School in Architectural and Landscape Heritage, Politecnico di Milano, Milan, Italy, virna.nannei@mail.polimi.it \\ ${ }^{2}$ Department of Architecture and Urban Studies, Politecnico di Milano, Milan, Italy, paolomariafarina@gmail.com \\ ${ }^{3}$ Department of Engineering and Applied Sciences, University of Bergamo, Bergamo, Italy, giulio.mirabella@unibg.it \\ ${ }^{4}$ Istituto per la Conservazione e la Valorizzazione dei Beni Culturali, Consiglio Nazionale delle Ricerche, Milan, Italy, \\ sansonetti@icvbc.cnr.it
}

KEY WORDS: Villa Galvagnina, integrated survey techniques, decay mapping, cultural heritage preservation

\begin{abstract}
:
On May 20, 2012, an earthquake of magnitude $M L=5.9$ hit a vast area of the Po Valley, in the territory across Lombardia, Veneto and Emilia, with the epicentre close to Finale Emilia. The seismic event, unusually intense for the area, caused extensive damage to the built heritage, so that six years later many buildings are still waiting for the necessary restoration works. One of them is the Villa Galvagnina in Moglia, in the province of Mantua.

The damages caused by the earthquake made necessary emergency strengthening works. Alongside these emergency measures, the Local Office of the Ministry of Culture considered suitable to start more detailed studies on this neglected asset.

The present study is part of the Superintendence initiatives, concerning the mapping of the building materials, a survey about murals' decay, as well as the damage and crack patterns. The aim of this data acquisition campaign is to identify the main risk factors for the preservation of the villa and to identify possible strategies for the strengthening and conservation works. The article critically presents the working method adopted for the survey setting up. The data acquisition steps, the difficulties experienced, and the choices made are fully described and some preliminary considerations are also expressed on the main damage suffered by the villa and on the ongoing deterioration.
\end{abstract}

\section{INTRODUCTION}

On May 20, 2012, an earthquake of magnitude ML $=5.9$ hit a vast area of the Po Valley, in the territory across Lombardia, Veneto and Emilia, with the epicentre close to Finale Emilia. The seismic event, unusually intense for the area, caused extensive damage to the built heritage, so much that six years later many buildings are still waiting for the necessary restoration works. One of them is the Villa Galvagnina in Moglia, in the province of Mantua. This Renaissance hunting palace was not in use since decades, which is the reason of its severe deterioration, even though it displays very interesting mural paintings.

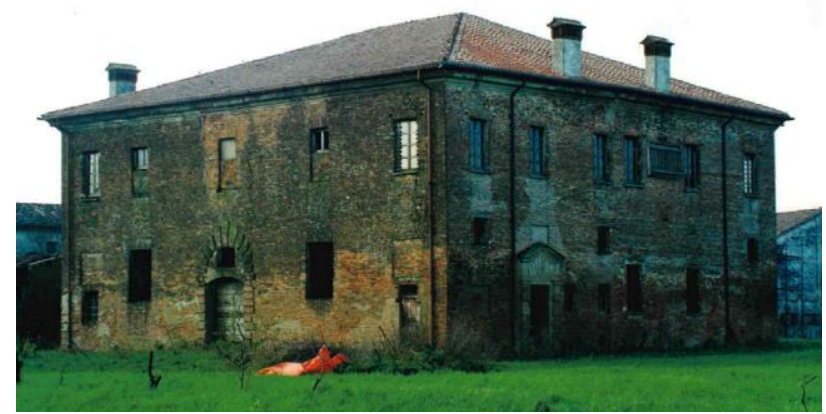

Figure 1: Villa Galvagnina in the 1990's (Private archive of Federico Merli)

The Villa presents the characteristic form of the two-storey country manors of the Mantuan Renaissance. The building has an almost square plan of about 22 meters on the sides, and an approximate eaves height of 10 meters. The original layout of the ground floor was defined by the entrance hall and various rooms located along both its sides. Later, a large reception hall has been created along the north-eastern elevation. The portals are the only external decorative elements, whereas the main hall and several rooms on the ground and first floors are richly decorated (Fringuellini, 1969).

The limited thickness of the masonry walls and the lack of connections between them, associated with the complete abandonment of the villa since the 1960s, led to a progressive deterioration of the ancient building. For this reason, several attempts have been made to preserve the structure from roofing refurbishment through the installation of provisional shoring. This shoring possibly prevented the villa complete collapse; in the meanwhile, the worsening of an alarming crack pattern together with the loss of considerable portions of the decorative apparatus was not avoided.

The damages caused by the earthquake made necessary emergency strengthening works, so that the Municipality of Mantua, the owner of the Villa, arranged the installation of an external reinforcement ring, consisting of a steel trusses and wires structure.

The former Superintendence for Architectural and Urban Landscaping in Brescia, Cremona and Mantua also set up a floor shoring, in order to make possible a first restoration of the main hall paintings cycle, gathering also the collapsed fresco fragments from the other rooms. Alongside these emergency measures, the Superintendence considered suitable to start more detailed studies on this neglected asset.

The present study, still work in progress, is part of the Superintendence initiatives, concerning the mapping of the building materials, a survey about frescoes' decay, as well as the damage and crack patterns. The aim of this data acquisition campaign is to identify the main risk factors for the preservation 
of the villa and to identify possible strategies for the strengthening and conservation works. For this purpose, the 1:50 scale drawings of the facades, of the floor plans and of two cross-sections of the building are being drafted, starting from the laser scanner point cloud surveys provided by the Municipality of Mantua, integrated by photogrammetric and direct surveys.

Preliminary drawings have been completed with the mapping of construction materials, of decay, and crack trend at a scale of 1:100. The mapping of the construction materials and decay at a scale of 1:50 are being prepared.

In order to go in depth in the direct observation of frescoes decay pattern, XRD analyses were also carried out on a group of samples taken in the main hall, in order to detect soluble salts species where some efflorescences are visible.

The article critically presents the working method adopted for the survey setting up, from the processing of the laser scanner clouds integrated with photogrammetric point clouds, to the drawing up of sheets for the collection and organization of data from the in-situ monitoring.

The data acquisition steps, the difficulties experienced, and the choices made are fully described and some preliminary considerations are also expressed on the main damage suffered by the villa and on the ongoing deterioration.

\subsection{Historical background}

Few studies have been conducted on the history of Villa Galvagnina, which for a long time remained far from the interest of scholars due to its isolated position in the countryside of the Mantuan Oltrepò. Recent archival research carried out by the Superintendence, as part of the initiatives to save the building taken after the earthquake, integrated Cavazzoli's indepth study (Cavazzoli, 1990 and Cavazzoli, 1998), but the results of this most recent investigations have not yet been published.

The interest in the building and its pictorial cycles appeared for the first time in 1927 when the discovery of frescoes belonging to the "Raphaelesque school and the school of Giulio Romano" was announced in the newspaper "Il Corriere della Sera" by the journalist Fernando Mantovani. Mantovani, writing to what was then the Superintendence of Monuments for the Provinces of Verona and Mantua, explained that "connoisseurs" have judged with caution the painting cycles found in the "beautiful residence that can be certainly considered belonged to the Gonzaga family" attributable to these schools. The name of Giulio Romano, the most illustrious master of the Mantuan Renaissance, was then immediately linked to the villa Galvagnina because of the paintings in the main hall that recall those of Palazzo Te. While there is no evidence to support this argument, it has for a long time influenced the studies on the villa. Mantovani also reported that he had prevented the complete covering of the works: even then the preservation of the painting cycles was under threat (ASB, 1927, 18061).

A letter written, according to the report in the file, by the Superintendent of monuments, marquis Da Lisca, to the Superintendent of Medieval and Modern Art for the Provinces of Trento, Verona, Mantua and Bolzano, attributed the cycles to some artists who worked at Palazzo Ducale such as Lorenzo Leonbruno, and assumed that they could be dated back to 1525 (ASB, 1927, 18087).

Other letters sent in those years by Mantovani to the Superintendence reiterated the hypothesis that Villa Galvagnina had belonged to the Gonzaga family. This assumption was supported by Fringuellini because of a document that testifies the transfert of the ownership of lands from the Gonzaga family to the Galvagni in 1487. On these lands there was a building that could be identified with the villa (Fringuellini, 1989).

At present, the oldest document known that certainly refers to Galvagnina is the will of Giovanni Battista Galvagni written in 1549 "in domo infrascritti domini testatoris siti in loco Galvagnine". It shows that by the middle of the $16^{\text {th }}$ century the villa already existed and belonged to the Galvagni family (Cavazzoli, 1998).

Concerning the painting cycles, the most accredited hypothesis is that they date back to the end of the 16th century and that Giulio Rubone and Ippolito Andreasi were among the artists who made them (Cavazzoli, 1998 and L'Occaso, 2009).

\section{DEVELOPED METHODOLOGY}

\subsection{Workflow}

Because of the state of total abandonment, the richness of the interior decorations, and the presence of internal and external reinforcement structures, the study of the building and of the risk factors that could affect its preservation is a very complex issue. It requires a careful planning, multiple techniques and tools and the involvement of various professionals. Consequently, the survey campaign, still in progress, had to be structured into different working phases, with a gradually increasing accuracy in the data acquisition and restitution.

First stage: quick geometric surveys and mapping of the construction materials and decay patterns at a scale of 1:100. In the aftermath of the earthquakes of 2012, the Municipality of Mantua commissioned a laser scanning survey of the villa, which was the basis for the preliminary mapping of the crack pattern and decorated surfaces, at a scale of 1:100, described in this study.

The specifications required by the Municipality for the laser scanning survey are not known, but it was made in a short space of time, during the installation of the reinforcement system.

The fast mapping of the materials and decay patterns was required by the Superintendency to estimate the costs of the restoration works. The quick survey made it possible to identify the main deterioration phenomena of the painting cycles and the possible damage mechanisms of the structure.

The survey based on the visual observation has been completed taking some samples from the frescoes in the main hall for XRD analyses.

Second stage: detailed geometric surveys and mapping of the construction materials and decay patterns at a scale of 1:50.

The University of Bergamo kindly provided a Faro Photon 120 laser scanner to conduct a research on the best practices for the laser scanning survey of a façade when there is a scaffolding. Photogrammetric techniques and direct survey methods will be used to integrate the survey where needed. The goal of the ongoing research is to obtain a survey in a scale at 1:50 that will be the basis for a detailed mapping of the construction materials and deterioration pattern. The drawings will be completed by descriptive sheets.

At the same time, the Municipality entrusted an architect to plan the investigation on the painting cycles.

Third stage: stratigraphic analysis

When the materials mapping will be concluded, a stratigraphic analysis will be conducted, the importance of which is clear to improve the historical knowledge of the hunting palace (Boato, 2008 and Doglioni, 1997). This analysis will also contribute to 
the understanding of the structural behaviour of the building. All the data collected during the survey campaign can be collected in a raumbuch that show the characteristic of each room of the villa.

\subsection{Geometric survey}

Two possible strategies have been identified to obtain a detailed survey of the villa. The first one is to make further laser scans moving the instrument on a denser grid. This solution is particularly necessary for the façades, because of the reinforcement system that makes it difficult to use photogrammetric techniques. Great attention is being devoted to defining the scanner positions, in order to acquire data on the part of the building covered by the shadow of the reinforcement structure. Seven acquisition of each front will be performed, at different distances. To limit the duration of the data acquisition, the scanner configuration will be set to both the horizontal and vertical range angles reduced as much as possible.

A photogrammetric survey is being conducted in an effort to enhance the accuracy of the data collection (useful suggestion on how to run a proper photogrammetric survey may be found in Historic England, 2017). The main difficulty, in this case, is the impossibility of taking photos at different heights to bypass the reinforcement system. To overcome this problem, different photos schemes at different distances from the façade are being tested, as well as two different photogrammetric software, Agisoft Metashape and 3D Flow Zephir.

Photogrammetry will also be used for the integration of the interior survey: better results are expected, since the reinforcement system is not close to surfaces such as the external one.

\subsection{Construction materials survey}

A preliminary mapping of the decorated plasters of the accessible rooms was carried out at a scale of 1:100. This mapping merges data concerning the construction materials and the decay phenomena. This unusual choice was determined by a request from the Superintendence, which needed maps for the determination of the decorated surfaces and a quick estimate of the costs of the restoration of the plasters. This is a rapid and summary analysis that is nevertheless adequate to a scale of representation with the restitution scale of 1:100.

With the help of the photogrammetric techniques, a survey of the construction materials at a scale of 1:50 scale is being carried out. It must include the paving and the wooden floors, most of which are painted, but seriously damaged.

The bricks bonds are visible only in the façades. A mensiochronological study could be useful to determine the dating of the building; however, currently, insufficient data for this area are available from literature. It should also be remembered that the method must be applied with caution for the possible presence of re-used materials.

The masonry is in a very poor condition, due to the presence of many bricks subject to powdering, as well as to the deep disintegration of the mortar joints.

The data acquired from visual observation of the materials are being classified using specific datasheets, with the purpose of a conservation project, and will be integrated through the diagnostic campaign commissioned by the Municipality.

\subsection{Crack pattern survey}

At the current stage of the research, the survey of the crack pattern was carried out on the façades and on the rooms secured by the safety works conducted by the Superintendence: each of the ground floor rooms, with the exception of room number 11 (Fig. 2), and the rooms number 24, 27 and 28 on the upper floor (Fig. 3). However, a preliminary crack pattern of some other rooms could be outlined, on the base of the laser scanning survey. This draft has to be validated by a direct inspection.

The comparison between some pictures taken in the 1960s and the ones taken in the 1990s made it possible to express some interesting observations on the structural condition of the villa before and after the seismic events of 2012. A schematic drawing of the crack pattern of the façades and rooms at a scale of 1:50 is being set up, along with the cataloguing of the cracks. Each sheet will accurately describe the appearance of the crack, the direction of the trace and the possible causes.

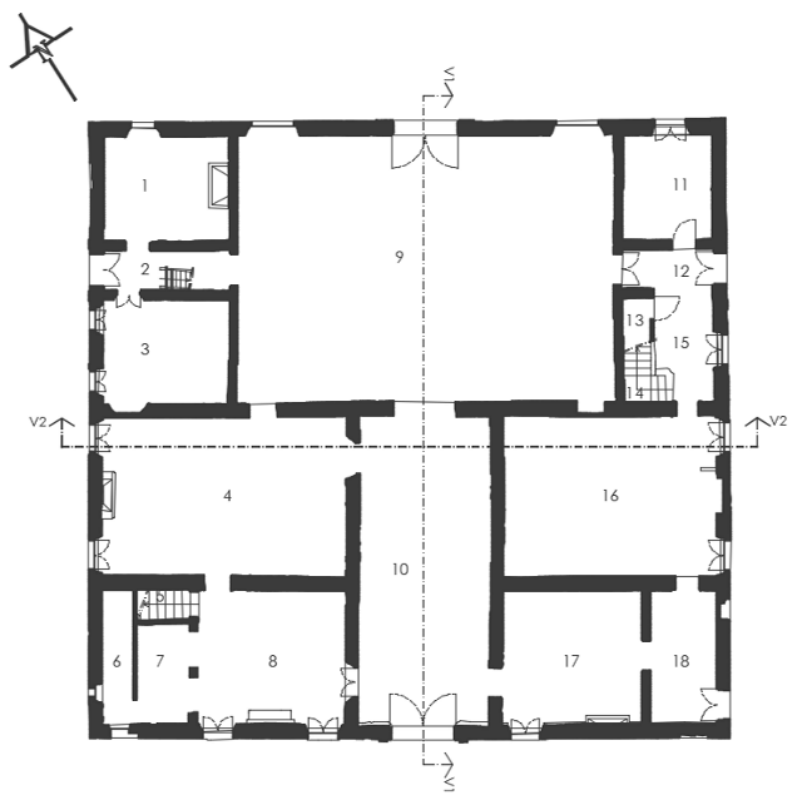

Figure 2: Ground floor plan H1 obtained from the points cloud (Municipality of Mantua).

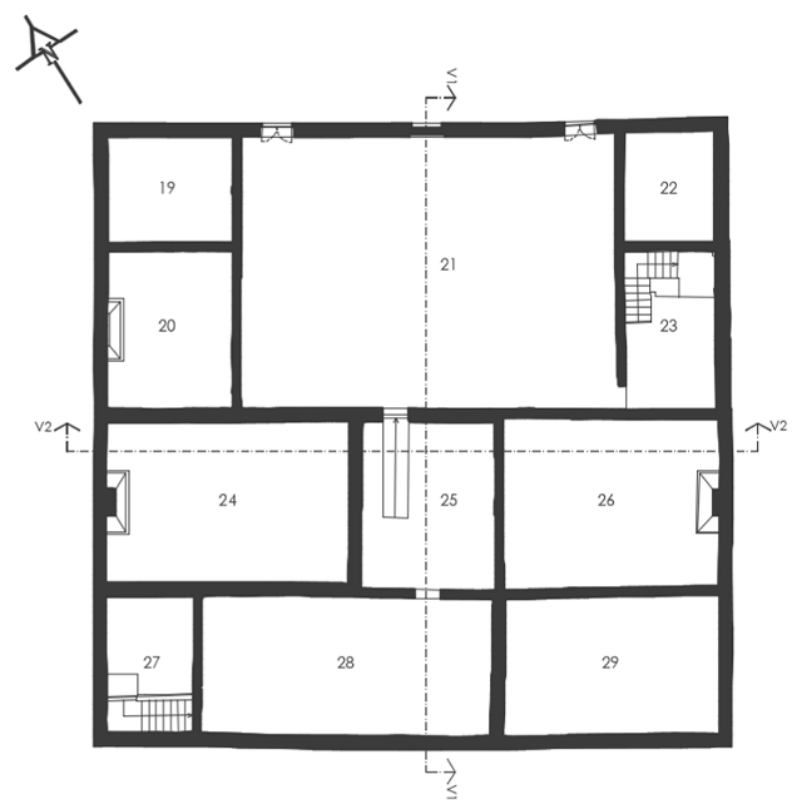

Figure 3: First floor plan $\mathrm{H} 2$ obtained from the points cloud (Municipality of Mantua). 
Structural scheme of the building.

The structural scheme of the Villa Galvagnina fits the typical layout of historic Italian buildings, with masonry walls and wooden floors and roofs. There are no vaulted roofs. The wooden framework of the roof was completely renovated during the 1990s. Three wooden trusses support the roof above the main hall: these trusses are not aligned with the built beams of the ceiling of the hall, a negative factor for the masonry structure. There are no other trusses, so the wooden roof seems to exert an outward thrust on the masonry walls. This hypothesis must be checked by a study of the connection details of the main beams on top of the masonry walls.

The villa has an approximate axially symmetric plan that is a positive factor for the seismic behaviour of the structure. However, the vertical organization of the spaces is not symmetrical, since the reception hall has a height of 7.3 meters, greater compared to the other rooms of the first floor, which is about 5 meters (Fig. 4). This difference determines a bad seismic behaviour, because of the absence of a horizontal diaphragm and the lack of a good tie rods reinforcement. An accurate survey of the steel anchor plates is indispensable in order to understand the structural behaviour of the building. Only a handful of steel anchor plates is visible on the façades, so it would seem that the structure cannot even count on the minimum contribution that a system of coplanar wooden floors joined to the walls could have provided.

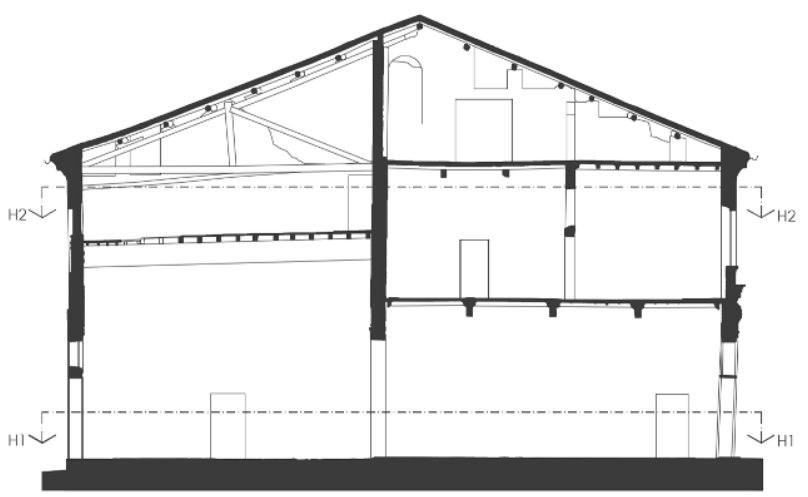

Figure 4: Vertical section V1 obtained from the points cloud (Municipality of Mantua).

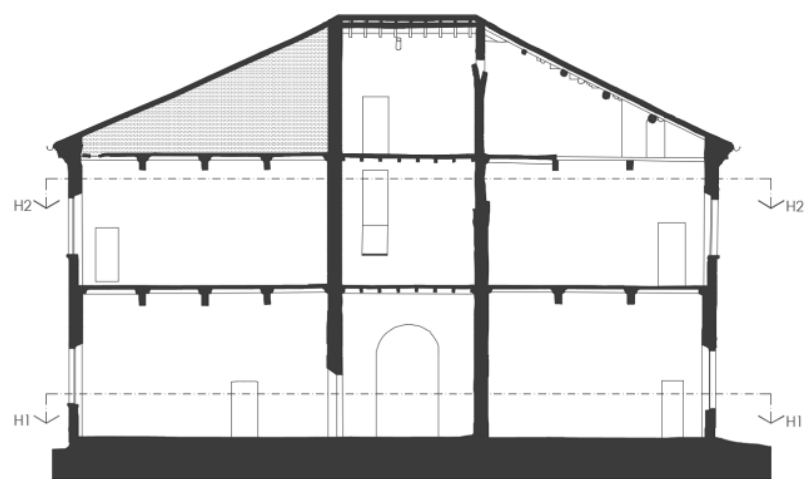

Figure 5: Vertical section V2 obtained from the points cloud (Municipality of Mantua).

The restoration project may use wooden roof strengthening techniques that transform the roof pitches into anti-seismic shear-resisting diaphragms. A good tie rods reinforcement is also indispensable in order to trigger in the building a box behaviour, as well as to counter the potential push of the roof. Following a visual observation of the external shell, the masonry structure shows many changes over time, so a careful stratigraphic analysis is required. For example, some changes in the opening positions can be recognized thanks to the discontinuities in the masonry pattern, just like the partial closure of three windows on the north-eastern front, in order to insert the main hall floor.

The outer brick walls and the brick walls of the main rooms are characterized by a thickness between 45 centimetres and 50 centimetres and a height of about 10 meters. The entrance hall walls, as well as the dividing wall between the main hall and the entrance hall, reach a height of about 14 meters (Fig. 5), so they have a remarkable slenderness.

As mentioned before, the low-quality mortar has caused the deep disintegration of the joints.

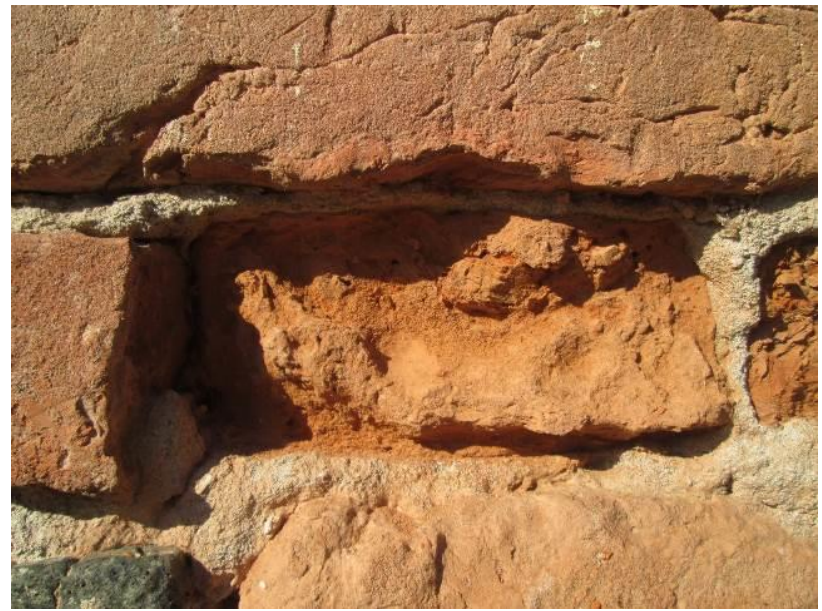

Figure 6: Powdering of the bricks.

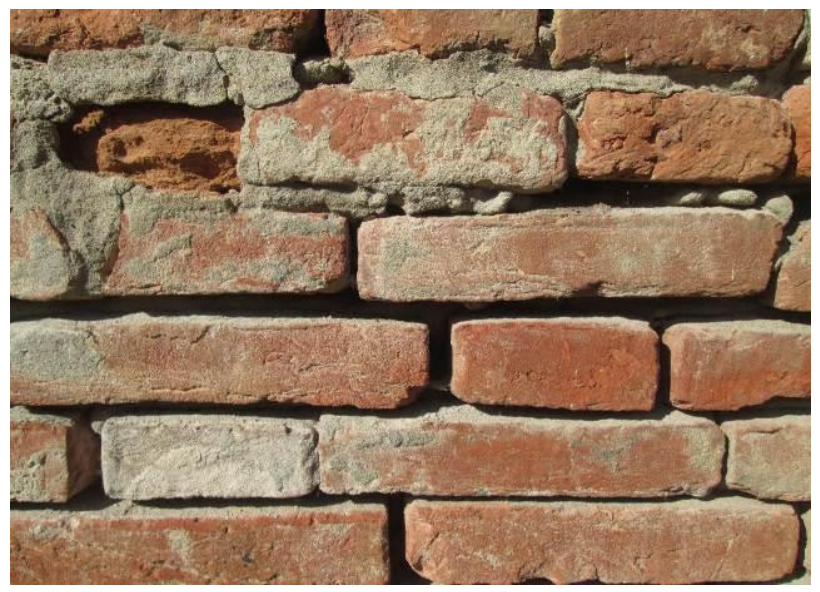

Figure 7: Loss of the mortar.

The only information currently available on the masonry are those derived from the direct observation of the façades. In order to better estimate the mechanical properties of the walls, the characteristic of the wall section must be verified, for example through sonic tests, to determine the masonry typology and the state of the brick-mortar bond. The possible use of flat jack tests requires much caution because of the poor quality of the materials; penetration tests on the mortar joints could also be difficult to carry out and not provide useful results.

\section{Analysis of the crack and deformation patterns}

The horizontal sections obtained from the points cloud show two deformation mechanisms of the masonry walls. The southeastern and the south-western walls show an out-of-plane 
deformation that could be due to a horizontal bending (Fig. 8). This deformation may have been caused by the earthquake and aggravated by the action transmitted by the internal walls. The internal walls and the south-west and north-west external walls also show a little out-of-plan deformation.

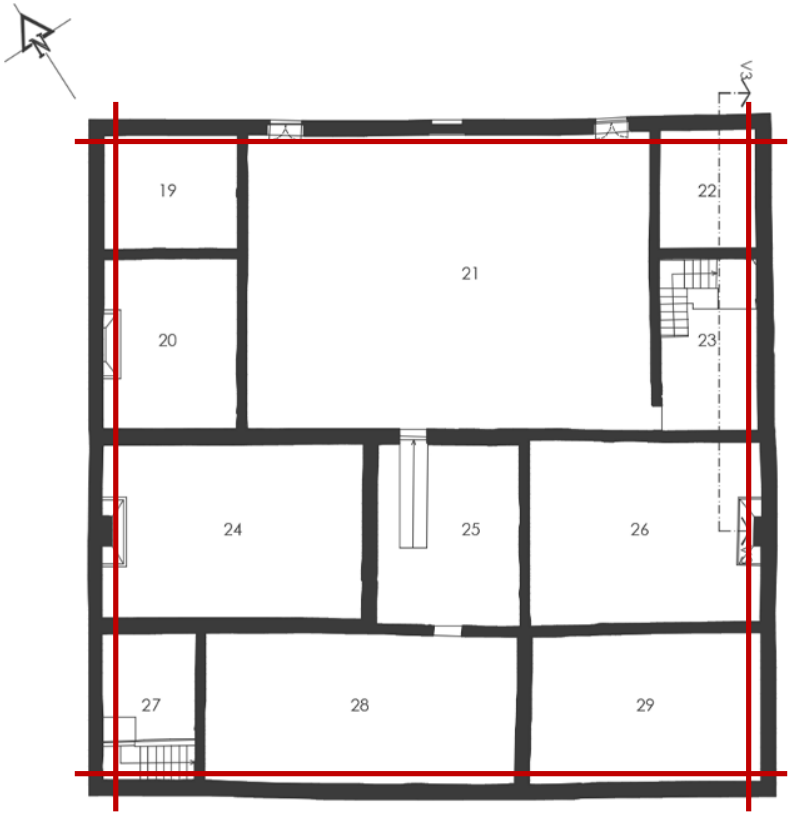

Figure 8: First floor plan H2, out-of-plane deformation of the masonry walls (Municipality of Mantua).

An outward rotation of the upper east corner of the building seem to be caused by the load of the roof, maybe exacerbate by a foundation subsidence, given a confined floor sinking (Fig. 9).

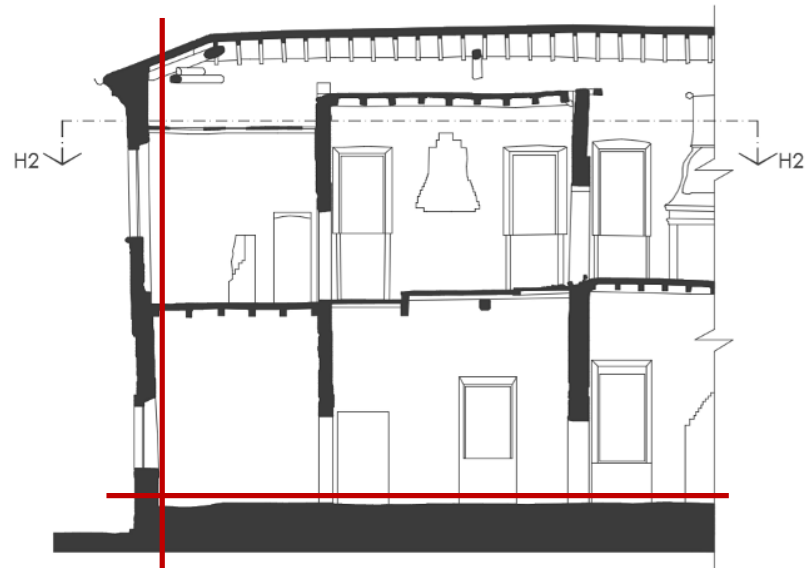

Figure 9: Vertical section V3, the overturning of the external walls and the floor sinking (Municipality of Mantua).

The vertical sections show the overturning of the external walls, particularly evident in the middle part of the wall, except for the north-eastern front, the maximum overturning of which is near the east corner.

The crack pattern appears in general to be due to static loads. It is from before the earthquake and the seismic event made him worse, as shown by the comparison between the photos taken before and after 2012 .

The cracks at the top of the external walls, in particular, appear to have been caused by the outward thrust of the roof (Figure 12 and 13). This problem, as already mentioned, does not seem to have been effectively solved by the replacement of the wooden structure.

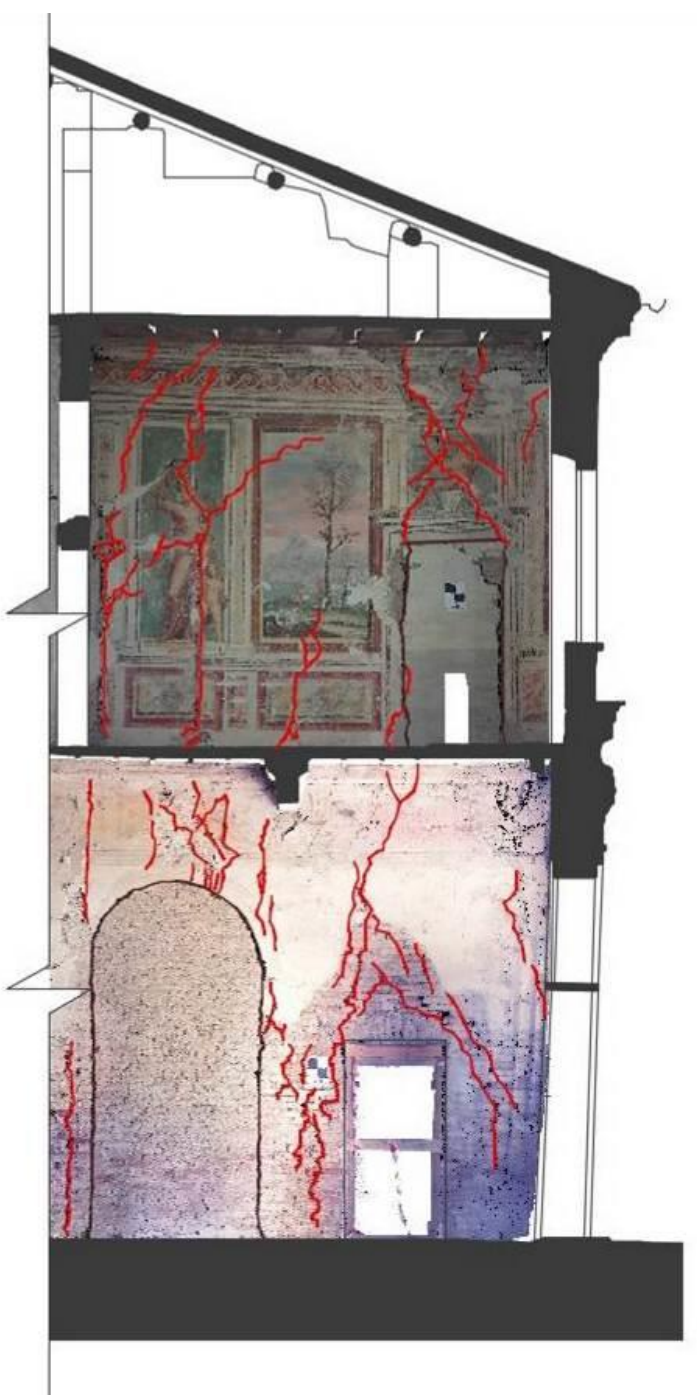

Figure 10: Details of the crack pattern.

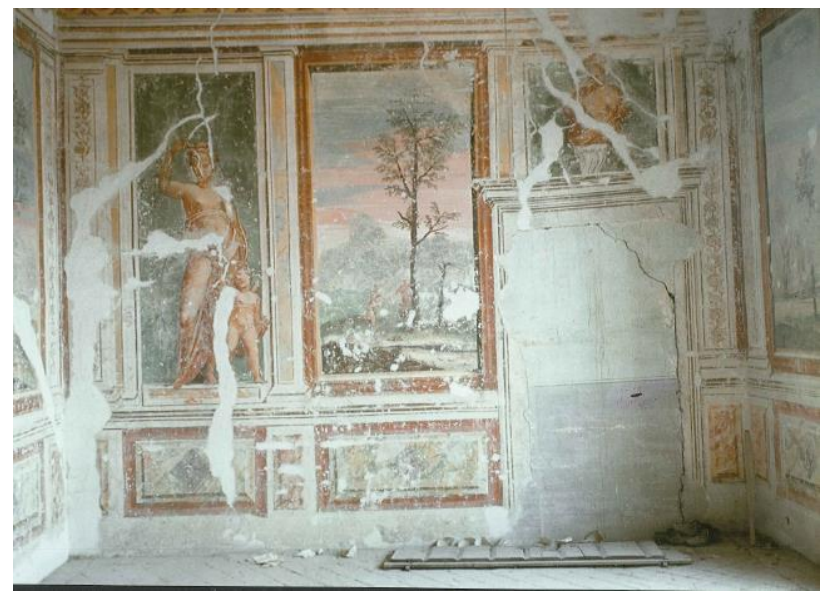

Figure 11: Crack pattern, room 28, 1990 (Private archive Federico Merli).

Another obvious problem concerns the severe damage suffered by the painted wooden floors that show localised rottenness and collapses. The structural behaviour of all the wooden elements will have to be thoroughly investigated in order to develop an 
effective strengthening action. The wooden floors behaviour under static and seismic loads can be improved by means of a thin collaborating steel slab or collaborating multilayer panels. Both of these techniques, while giving up the intactness of the pavement, make it possible to build anti-seismic shear-resisting, even if the multilayer panels lead to worst results in terms of flexural response.

Particular attention should be given to the built beams of the main hall, one of which was replaced by a glulam beam. The ends of the built beams were repaired using steel plates.

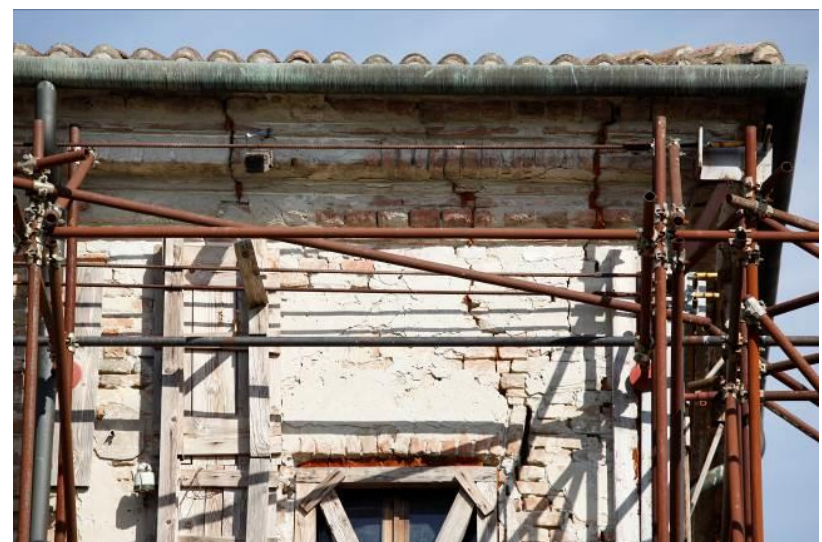

Figure 12: Cracks due to the outward thrust exerted by the roof.

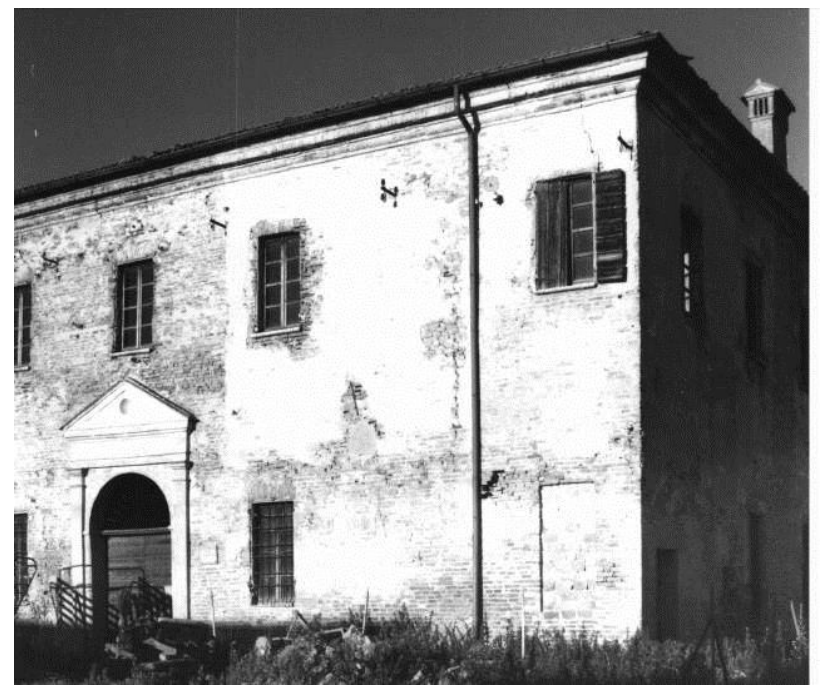

Figure 13: The main front of the villa in the 1960's. The crack due to the outward thrust exerted by the roof can be seen in the upper right corner (Private archive Alberto Ferrari).

\subsection{The state of conservation survey}

\section{Direct surveys}

Given the complexity of the painting cycles of the Villa Galvagnina and the possibility, at present, of carrying out only a visual inspection of the materials and structures, the identification of alteration and decay phenomena has proved to be a complex issue (an important reference on this subject can be found in Dimes and Ashurst, 1998). Nevertheless, visual analysis led to find out the main causes of the serious deterioration of the building (Musso, 2010).

As anticipated in paragraph 2.3, the outcomes of the inspection were depicted in preliminary drawings at a scale of 1:100. A more detailed mapping is being prepared at a scale of 1:50; the data-gathering system also uses two type of specific datasheet. The "Material forms of alteration and decay analysis" sheets describe all the anomalies found on masonry structures, wooden elements and pavements, while the "State of conservation of the wall paintings analysis sheets" collects all information on the condition of the decorated plaster of each accessible room.

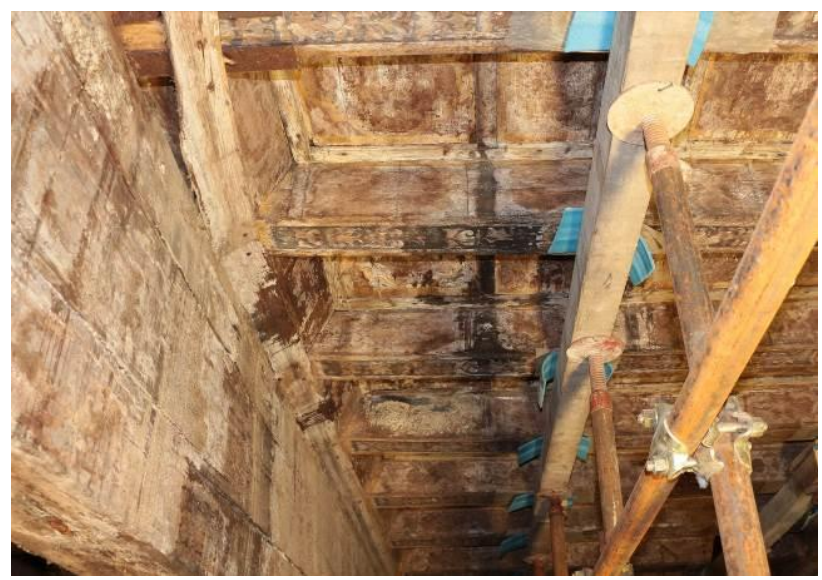

Figure 14: Wood decay, main hall.

The "Material forms of alteration and decay analysis sheets" are organized by the type of material and deterioration category which refer to the "ICOMOS-ISCS Illustrated glossary on stone deterioration patterns": crack and deformation, detachment, features induced by material loss, discoloration and deposit, biological colonization (ISCS, 2008). On the contrary, the terms for alteration and decay phenomena and their explanation are taken from the Italian document, "UNI-EN 11182: 2006. Beni culturali. Materiali lapidei naturali ed artificiali. Descrizione della forma di alterazione - Termini e definizioni". This choice allowed the development of a form system that facilitates the insitu data collection. The logical construction of the sheets permits to sort data in a way that makes the analysis of the damage causes easier. At the same time, the Italian nomenclature was chosen, because it is more succinct and well known to all the operators involved.

The sheets also contain an illustrative photograph of the observed phenomenon, the identification of the kind of process involved, the highlighting of any loss of material and the graphic symbol used for mapping the degradation phenomena. Finally, the sheets provide the location of the phenomenon in the building, the preliminary hypotheses on its causes and other observations.

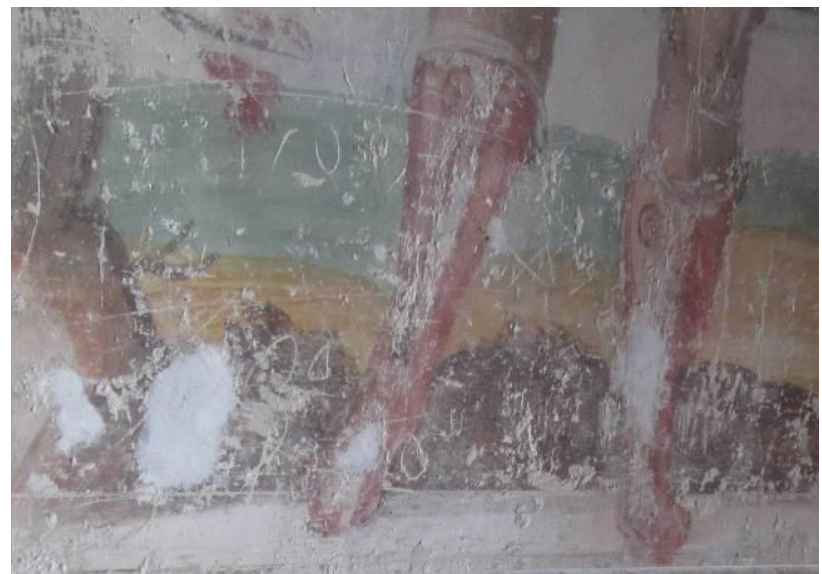

Figure 15: Wall paintings decay, room 4.

The analysis of the state of conservation of the wall paintings, although closely related to the more general issue of the condition of the masonry that is the support of the decorations, 
requires a specific approach, which involves the figure of the conservator. For this reason, the results of the inspections carried out on the painted surfaces of the villa were collected using the "State of conservation of the wall paintings analysis sheets".

The specific needs of the conservation works on the paintings required some additions to the terms that describe the forms of decay, partly borrowed from the forms proposed by Rella and Saccani (Rella and Saccani, 2009) and partly taken from the Icomos glossary (ISCS, 2008).

The sheets are organized in six sections. The first one gives the information about the location of the wall painting, relating to the building that houses it, the villa Galvagnina, and its position inside the structure.

The second section includes data relating to the environment: the type of building, the orientation and some data concerning the climatic conditions. As it was not possible to monitor the climatic conditions inside the villa, the data relating to the external environment collected by the Environmental Protection Agency of Lombardy were taken as reference. The paintings are located inside the building, so these data are not representative of the microclimate that affect their conservation. However, they can indicate a trend, although characterized by greater variability with respect to the microclimate inside the villa.

The temperature and humidity range inside the villa benefits from the inertia of the masonry structures, even though it should be emphasized that the building is not hermetically sealed and there is no air conditioning system. The climatic data relating to the external temperature and relative humidity, were collected by the sensor located in Gonzaga for a period running from January $1^{\text {st }}, 2008$ to December $31^{\text {st }}, 2017$. In those ten years a minimum temperature of $-14.1^{\circ} \mathrm{C}$, on February $3^{\text {rd }}, 2012$, a maximum temperature of $39.6{ }^{\circ} \mathrm{C}$, on August $22^{\text {nd }}, 2012$, and a maximum daily temperature range of $22.7^{\circ} \mathrm{C}$, on April $22^{\text {nd }}$, 2017, were registered. An average daily temperature range of $11.0^{\circ} \mathrm{C}$ was observed. The relative humidity data are most relevant for the cultural heritage conservation (Camuffo, 2014): a relative humidity of $100 \%$ was registered on numerous occasions, while the lowest relative humidity, equal to $12.7 \%$, was recorded on March $26^{\text {th }}, 2009$. On the same day, the maximum daily relative humidity range was recorded, equal to $87.2 \%$. An average daily relative humidity range of $42 \%$ was observed.

The third, fourth and fifth sections include the observations relating to the forms of alteration and decay of the painted plasters, divided according to the layer they concern: the masonry, the plaster or the pictorial layer.

The sixth section gives general notes on the state of the paintings, the seventh concerns some preliminary considerations on the preservation techniques and the last one contains the references to the possible attached documentation.

The visual investigation of the deterioration phenomena showed that the main causes of the extremely poor condition of the villa are neglect and abandonment.

On the decorations, in fact, in addition to the cracks, the gaps and the detachments determined by the structural problems of the building, significantly aggravated by the earthquake, the presence of deposits, cuts, scratches, impact damages and graffiti was observed.

In the main hall, moist areas due to the rainwater infiltrations from the roof can be seen. Despite the replacement of the windows during the last century, there are the characteristic signs of birds inside the villa.

The climatic conditions combined with the characteristics of the plasters have also determined a widespread presence of soluble salts, investigated through XRD analyses.

\section{XRD Analyses}

XRD Analyses have been carried out on three samples taken from the surface of mural painting in the Main Hall. The task regarded the identification of efflorescences components. Two of the samples highlighted the surface sulphation and the presence of weddellite (calcium oxalate dihydrate). The usual components of plaster are present as well, such as calcite, quartz and other silicates. For what concern the origin of calcite, this mineral phase could also come from re-crystallization process. This doubt could be solved by means by a more in-depth survey. Both gypsum and weddellite should be considered as decay products. Moreover, weddellite could have be generated by oxidation mechanism on former organic additives present in the mortar mix. The third sample does not contain decay products; hence it seems to put in evidence a less damaged surface.

\section{CONCLUSIONS}

The hunting palace Villa Galvagnina shows a state of decay mainly due to neglect and the abandonment, combined with important structural problems. The variety and complexity of the deterioration phenomena required a study structured in subsequent stages and the involvement of different actors and professionals.

At present, a geometric laser scanner survey has been completed by the Municipality, which is being integrated by the authors, and a preliminary investigation of the material forms of alteration and deterioration was performed, that make it possible to prepare some observations on the nature of these phenomena. A severe and widespread deformation and cracking pattern has been recorded, due to the slenderness of the walls and the poor quality of the masonry structure, characterized by poor materials and construction techniques and the lack of a good tie rods reinforcement. The damage caused by the seismic actions was added to a crack pattern determined by the thrust of the roof and maybe static overloads.

The structural consolidation is the most urgent priority in order to preserve the villa and allow a restoration of the paintings. As far as the static behaviour is concerned, the integration of the mortar joints is needed, as well as a detailed investigation on the state of the foundations and of the roof. Concerning the seismic behaviour of the building, setting up a good tie rods system at the level of the first floor and at the level of the roof is essential, as well as a diaphragm in order to trigger the box behaviour of the structure. The floors layout suggests the possibility of putting in place an anti-seismic roof.

As regards the painting cycles, the recovering works operated by the Superintendence on the main hall must be concluded. Indepth considerations may be made on the basis of the results of the forthcoming diagnostic campaign.

It should be noted, however, that the opportunity of the reuse of the building must be carefully examined by the municipality. A peculiar feature of the villa Galvagnina, in fact, is the total absence of technical equipment. So, firstly, an extensive work would be necessary in order to make the villa suitable for functions other than cultural visits and, on the other hand, the insertion of an air-conditioning system would cause a considerable stress for the decorated plasters.

After the conclusion of the stratigraphic analyses, an interesting development of this research could be the use of the most recent three-dimensional modelling techniques in order to document the changes that the building undergone over time. The virtual reality can make these changes easily understandable and 
available to a non-expert public, without any need for reconstructions that affect the authenticity of the historic building.

\section{ACKNOWLEDGEMENTS}

The authors would like to acknowledge the Municipality of Mantua for providing the laser scanning survey, restorer Federica Manna for collaborating in the mapping of materials and decay, the Superintendence and architect Basso Bert for giving to the authors the opportunity to conduct this study.

\section{REFERENCES}

[ASB] Former Superintendence for Architectural and Urban Landscaping in Brescia Archives, Cremona and Mantua, $4^{\text {th }}$ November 1927. "Mantovani Fernando to the Superintendence of Monuments for the Provinces of Verona and Mantua". Former Superintendence for Architectural and Urban Landscaping in Brescia, file 35/B (MN), binder 1, code number 18061.

[ASB] Former Superintendence for Architectural and Urban Landscaping in Brescia Archives, $9^{\text {th }}$ November 1927. "Superintendent Marquis Da Lisca to Superintendent of Medieval and Modern Art for the Provinces of Trento, Verona, Mantua and Bolzano". Former Superintendence for Architectural and Urban Landscaping in Brescia, file 35/B (MN), binder 1, code number 18087.

Boato, A., 2008. L'archeologia in architettura. Venezia: Marsilio Editori.

Camuffo, D., 2014. "Microclimate for Cultural Heritage. Conservation and Restoration of Indoor and Outdoor Monuments". Amsterdam: Elsevier.

Cavazzoli, F.M., 1991. "Decorazioni e affreschi cinquecenteschi nel palazzo della Galvagnina". Master's thesis, Università degli Studi di Bologna.

Cavazzoli, F.M., 1998. "Contributo all'attribuzione delle decorazioni del palazzo della Galvagnina". Civiltà mantovana, 3, XXXIII, 106, 29-44.

Doglioni, F., 1997. Stratigrafia e restauro. Tra conoscenza e conservazione dell'architettura. Trieste: Lint.

Dimes, F.G. and Ashurst, J., 1998. Conservation of Building and Decorative Stone. Oxford: Butterworth-Heinemann Ltd.

Fringuellini, M.G., 1966. "Un misconosciuto avanzo di arte giuliesca: la Galvagnina vecchia presso Moglia", in [AIM] Associazione Industriali Mantova (Ed.), Palazzi e ville del contado mantovano. Firenze: Vallecchi.

Fringuellini, M.G., 1989. "Lo 'spirito giuliesco' della Galvagnina Vecchia", Proceedings of the international conference "Giulio Romano e l'espansione europea del rinascimento". Mantova: Accademia Nazionale Virgiliana.

[HE] Historic England, 2017. Photogrammetric Applications for Cultural Heritage. Guidance for Good Practice, Swindon: Historic England. https://historicengland.org.uk/images-books/publications

[ISCS] ICOMOS International Scientific Committee for Stone, 2008. Illustrated glossary on stone deterioration patterns. Champigny sur Marne: ICOMOS

L'Occaso, S., 2009. "Disegni e dipinti per il tardo manierismo mantovano". Prospettiva: rivista di storia dell'arte antica $e$ moderna, 136, 35-46.

Musso S.F., 2010. Recupero e restauro: guida pratica al rilievo e alla diagnostica. Roma: EPC Libri.

Rella, L., and Saccani, L., 2009. Schede tecniche per il restauratore: di dipinti murali, su tela e su tavola. Milano: Editore Ulrico Hoepli

UNI 11182:2006. Beni culturali - Materiali lapidei naturali ed artificiali - Descrizione della forma di alterazione - Termini e definizioni. 